WellBeing International

WBI Studies Repository

1992

\title{
Animals, Archetypes, and Popular Culture: Tales from the Tabloid Press
}

\author{
Harold A. Herzog \\ Western Carolina University \\ Shelley L. Galvin \\ Western Carolina University
}

Follow this and additional works at: https://www.wellbeingintlstudiesrepository.org/acwp_ailae

Part of the Animal Studies Commons, Other Anthropology Commons, and the Social and Cultural Anthropology Commons

\section{Recommended Citation}

Herzog, H. A., \& Galvin, S. L. (1992). Animals, archetypes, and popular culture: Tales from the tabloid press. Anthrozoös, 5(2), 77-92.

This material is brought to you for free and open access by WellBeing International. It has been accepted for inclusion by an authorized administrator of the WBI Studies Repository. For more information, please contact wbisr-info@wellbeingintl.org.

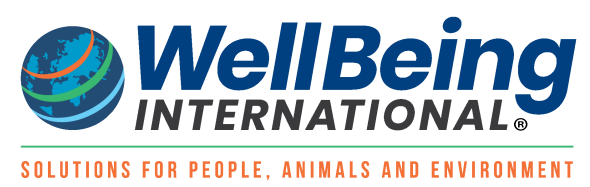




\title{
ANIMALS, ARCHETYPES, AND POPULAR CULTURE: TALES FROM THE TABLOID PRESS
}

Harold A. Herzog, Shelley L. Galvin

Western Carolina University

\begin{abstract}
This paper characterizes the portrayal of animals and human-animal relations in one genre of American popular culture - the "supermarket" tabloid press. A total of 789 animal-related stories and photographs in 82 issues of four tabloid magazines were analyzed according to theme. The items fell into nine categories in which animals were portrayed as objects of affection, saviors, threats, victims, things to be used, sex objects, imaginary and mythological beings, surrogate humans, and objects of wonder. It is argued that these themes represent archetypes reflecting the roles that animals have had in human cultural and psychological life since the historical origins of our species.
\end{abstract}

\section{INTRODUCTION}

The images inscribed on the walls of the Caves of Lascaux by Upper-Paleolithic artists are stunning evidence of the central role of animals in the culture and mythology of our not-so-distant ancestors. Analogous images and myths in our society are reflections of how modern Americans relate to other species. In this article, we consider the archetypical nature of animal-related items published in one genre of popular culture, the supermarket tabloid. Like the ancient paintings at Lascaux, tabloid stories are products of the human imagination and, as such, are reflections of the multiplicity of roles that animals play in our cultural and psychological lives.

Baenninger (1988) and Kellert and Westervelt (1982), respectively, have shown that historical changes in attitudes toward animals can be traced through the portrayal of animals in paintings and in newspaper accounts. Their work demonstrates that the analysis of media can provide insight into social attitudes towards other species. There are few studies, however, that describe the portrayal of animals in current popular culture. Images of animals are ubiquitous in American mass media (Bryant 1979), but no audiovisual or print media consistently contains the diversity of stories about animals and their relations with people as do the weekly news tabloids found at supermarket checkout counters.

The tabloids clearly appeal to large numbers of Americans. The four tabloids used in our research have a combined circulation of over six and a half million (National Directory of Magazines 1989). The National Enquirer (NEn), the exemplar of this genre, has a circulation of just over 4,500,000 (Manning 1989) and an estimated annual revenue of $\$ 130$ million (Fox 1988). The National Examiner (NEx), with a circulation of $1,100,000$, follows in popularity, trailed by the smaller but no less sensational Weekly World News $(W W N)$ (circulation 600,000) and Sun (circulation 500,000) (Manning 1989).

Despite their popularity, the tabloids have been largely neglected as objects of study by students of American popular culture (Kelm 1990). There is debate about the demographics of the readership (Nordheimer 1988; Salwen and Anderson 1984) and the reasons that people read them. Interpretations of the social function of tabloids range from simple entertainment (Salwen and Anderson 1984) to information seeking (Lehnert and Perpich 1982). On the other hand, Levin, Mody-Desareau, and Arluke (1988) view the tabloids as agents of social control, the goal of which is to "reinforce the status quo...by discouraging discontent and protest and by supporting prevailing norms and values" (p. 517). 
We examined nearly 800 articles and pictures published in four tabloids over a five-year period as reflections of the diverse roles that animals play in the psychic lives of 20th-century Americans. Often, animal stories in these papers are bizarre and scarcely believable, the headlines inviting incredulity. For example, a recent article in the National Examiner (11/22/88) entitled "Employee Assaulted with a Deadly Bird" did not describe an avian rogue run amok, but an incident in which a shoplifter threw a frozen chicken at a store manager. However, whether there was even a grain of truth to these articles is quite irrelevant for our purposes; we view these stories much as an anthropologist views myths-tales that shed light on how we relate to the world.

\section{METHOD}

Between 1985 and 1990 approximately 100 issues of the four tabloid papers listed above were obtained. A computer database was constructed using 82 of these papers randomly selected from our collection. This sample consisted of 35 issues of Sun, 19 issues of WWN, 15 issues of NEX, and 13 issues of NEn. To form the computer database, we identified every article, picture, cartoon, or column dealing with animals or depicting human-animal relations in each of the 82 issues. Once identified, each item was categorized as to the themes represented, species involved in the story, the title, tabloid, and issue. The thematic categories are described below. Some stories incorporated multiple themes. For example, a story entitled "Saved from the Jaws of a Black Bear... By the Pup She Was Giving Away!" (NEn 1/1/85) included themes related to animals as saviors, as threats, and as objects of human affection. Thus, the category system was designed so that an item could be placed in more than one category. The final database consisted of 789 items: 338 from Sun, 199 from WWN, 134 from NEn, and 118 from NEx. Because every item pertaining to animals in each issue was included, we feel that the sample accurately reflects the view of animals presented in the tabloid press.

Table 1. Distribution of Themes by Publication ${ }^{\mathrm{a}}$

\begin{tabular}{|lcccc|}
\hline \multirow{2}{*}{ Themes } & \multicolumn{4}{c|}{ Publication } \\
\cline { 2 - 5 } & $\begin{array}{c}\text { NEn } \\
(\mathbf{n}=\mathbf{1 3 4})\end{array}$ & $\begin{array}{c}\text { NEx } \\
(\mathbf{n}=\mathbf{1 1 8})\end{array}$ & $\begin{array}{c}\text { Sun } \\
(\mathbf{n}=\mathbf{3 3 8})\end{array}$ & $\begin{array}{c}\text { WWN } \\
(\mathbf{n}=\mathbf{1 9 9})\end{array}$ \\
\hline Loved one & 50.9 & 39.0 & 32.5 & 22.1 \\
Savior & 3.7 & 6.8 & 4.7 & 5.5 \\
Threat & 6.0 & 11.0 & 16.6 & 26.1 \\
Victim & 3.7 & 15.3 & 15.4 & 17.6 \\
Tool & 9.0 & 11.8 & 13.6 & 14.0 \\
Sex object and sexual aggressor & 1.5 & 2.5 & 3.6 & 0.5 \\
Imaginary animal & 1.5 & 9.3 & 11.5 & 9.5 \\
Person & 27.0 & 8.5 & 14.7 & 5.5 \\
Object of wonder & 12.7 & 10.2 & 14.8 & 13.6 \\
Miscellaneous & 9.7 & 18.6 & 14.5 & 19.1 \\
\hline
\end{tabular}

${ }^{a}$ Numbers refer to percentage of article reflecting the theme.

Occasionally, some rather arbitrary decisions about the coding system had to be made. Perhaps the most fundamental was, What precisely is an animal? Space aliens, for example, were not considered to be animals for the purpose of the study. Stories about Bigfoot and werewolves, however, were included. (The decision to not consider space aliens may have been an error; one article chronicled a case in which a woman was impregnated by a space alien and subsequently gave birth to a puppy, suggesting that the alien may have indeed been an animal.) In contrast, on two occasions a fundamental taxonomic dichotomy was violated when we included trees as animals because they acted in an animate fashion (they killed greedy land developers). Recipes for meat dishes were not counted as animal articles, but stories in which the consumption of animals was the central point of the article (i.e., stories about people 
eating nontraditional food such as worms) were used in the study. The inter-rater reliability of the thematic classification system was assessed by having the two authors independently classify all 51 animal articles in four issues. The raters agreed on the classifications of $88 \%$ of the articles.

\section{RESULTS}

Every issue of the tabloids contained animal- related articles and pictures (an average of 9.6 animal items per issue). The tabloids were fairly consistent in the number of animal stories per issue; the average ranged from a low of 8.8 in the NEn to a high of 10.4 in the WWN. Though tabloids are commonly lumped together in the public mind, the four weeklies differed in how animals were typically portrayed. Table 1 indicates the percentage of the major themes in each of the tabloids. Contrast, for example, the thematic distribution of items in the NEn and the WWN. In the former, the majority of items depicted animals in a positive light (animals as objects of affection, wonder, and humor). In the latter, there was a higher percentage of more negative themes (animals as threats and victims of human cruelty).

\section{THEMES}

The primary goal of this analysis was to characterize how animals and human-animal relations were portrayed in American popular culture. Nine major themes emerged from the stories and photographs and are described below. Because of spatial limitations, the primary purpose of this paper is descriptive; it is concerned with depicting how animals are presented in this genre rather than providing an indepth analysis of the "meaning" of the stories.

Table 2. Distributions of Species in the Affection Category

\begin{tabular}{|cl|}
\hline Number of Articles & Species \\
\hline 60 & Dogs \\
20 & Cats \\
12 each & Apes and monkeys, birds, horses \\
5 & Turtles and tortoises \\
4 each & Animals in general, cows and bulls, dolphins, pigs \\
3 each & Bears, ducks, frogs, lions, tigers, snakes \\
2 each & Elephants, goats, lizards, mice, rats, wolves \\
& $\begin{array}{c}\text { Alligators, bats, butterflies, camels, chickens, cougars, deer, ferrets, fish, foxes, guinea } \\
\text { pigs, hamsters, hedgehogs, killer whales, rabbits, sea elephants, scorpions, sloths, slugs, } \\
\text { spiders, squirrels, walruses, water buffaloes }\end{array}$ \\
\end{tabular}

\section{The Animal as Loved One}

Americans spend well over $\$ 7$ billion on about 450 million pets each year (Serpell 1986). Thus, it is no surprise that the most frequent theme of both articles and pictures in the supermarket tabloids was affection between people and animals or between animals of the same or different species. The 267 articles in the broad category of affectionate relations with and between animals typically took one of several forms: weird pets, extreme devotion by either the animal or the owner, and cute animal pictures. The species portrayed in this thematic category are shown in Table 2. Note, on the one hand, the dominance of dogs and cats, the traditional pets in our culture, and on the other, the impressive diversity of species listed. Photographs depicting the relations between individuals with unusual pets typically took the form of images of individuals bathing, kissing, or caressing an assortment of pet tigers, elephants, chickens, alligators, snakes, spiders, etc. The large number of wild animals such as lions and elephants portrayed as human friends suggests that Americans have a "Mowgli fantasy" in which we imagine ourselves as masters of and communicators with wild beasts, much like the hero of Kipling's The jungle Book. 
A second category of affection stories portrayed extreme relations between owners and their pets. Examples included "Pet Lover Had Horse Move in with Him" (Sun 1/9/90); "After Pooch Dies, HeartBroken Vet Kills Herself with a Lethal Injection" (Sun 5/8/90); and "New Fad...Stuff Your Dead Pet!" (WWN 8/4/87). Stories about the miraculous reappearance of long-lost pets and owners offering huge rewards for the return of missing kitties fell into this category, as did advice columns for pet owners. In the latter, animal lovers submitted Dear Abby type questions such as, Are mice scared of dead cats? (Sun $6 / 9 / 87$ ) and Is it ethical for me to pierce the ears of my pit bull dog so it can wear an earring? (WWN 4/9/85).

Some individuals have more intense relationships with their animals than with other people. Such was the case with the man who traded his bride for a goat (NEx 4/14/87), the trainer who preferred to live with his bears (Sun 7/10/90), and a host of dotty spinsters who left their inheritances to their pets: "Fat Cat Inherits $\$ 240,000 \ldots$ and A Five Room House" (Sun 3/11/86). The Sun regularly features a write-in column entitled "Why I Love My Pet." Campbell (1988a) argued that our society views animals as inferior life forms, and it has been claimed that we suffer an intellectual and emotional separateness from other species (ten Bensel 1984). In our culture, the preference for animals over people borders on taboo, and tabloid pet stories may provide a medium for breaching the cultural dichotomy between the species.

Generic "cute animal pictures" were one of the most common manifestations of the affection theme. These are operationally defined by the involuntary response "Oooh, isn't that cute!" typically invoked by the photos. The vast majority of the 85 pictures reflecting this theme were pictures of newborn or juvenile animals, often depicted with human children. Neotony was the most salient feature of these pictures, and the subjects were almost inevitably endowed with classic Lorenzian baby releasers - big eyes, large heads, and short, stubby limbs-morphological characteristics shared with human infants, which stir misdirected parental feelings in human beings (Gould 1979; Lawrence 1989). Typical examples included pictures of a child sharing his playpen with his pet lion cub (NEn 9/24/85), a girl cradling a diapered chimp (Sun 11/1/88), a human baby and a young orangutan smelling flowers together, and children and adults kissing a bewildering variety of animals, ranging from camels to sea turtles.

Cute animal pictures were often flagrantly anthropomorphic. One manifestation was the projection of human affectional tendencies onto other species. For example, animals were often shown kissing conspecifics or playing with them. In another twist, the thrust of the item was that animals of different species can like each other: a cat and a parakeet drinking from the same water bowl (WWN 5/9/89), a killer whale feeding a seagull (NEn 3/18/86), a dog playing with dolphins (NEx 3/18/86), a tiger cub curled up with a colt (NEx 10/4/88). In other cases the anthropomorphic element in the cute animal pictures was that the animal engaged in a typically human activity: a big-eyed puppy with a basket of gifts, a bulldog sitting in front of an empty beer mug with a towel on his head and a hungover look in his eye. In an odd way, these pictures reinforce the feelings of connectedness we have with other species yet also emphasize the gap between us. Certainly, they reflect the strength of our tendency to attribute human characteristics, abilities, and desires to nonhuman animals (Lawrence 1989).

\section{The Animal as Savior}

One of the most powerful animal-related motifs in our cultural heritage is that of the animal as a savior. Lassie rescues Timmy, dolphins save drowning sailors, Jiminy Cricket keeps Pinocchio on the straight and narrow path, the woeful cocker spaniel Checkers salvages the early political career of Richard Nixon. The tabloid press has not neglected this theme, which was featured in 40 of the articles in our database. Mirroring their preeminent role in the affection category, dogs were also the most likely candidates to come to the rescue and were the subjects of half (20) of the savior stories in the database. Typically, dog savior stories took the form of "Loyal Mutt Saves Drowning Boy" (WWN 3/25/86); "World's Tiniest Hero" (Sun 5/8/90), a story describing how a chihuahua dragged its mistress from her bed during a house fire; and the classic "Faithful Dog Takes a Bullet to Save Her Master's Life" (WWN 4/18/90). The dog-as-asavior is a manifestation of the dog's role as the object of the strongest human-animal bond, and in most stories it was the animal's bond to a human that mediated the rescue. Occasionally, however, the saving act is the result of love, not toward its master, but by its master. This was the case in an article about a man who was wakened from a coma after hearing his beloved dog howling (NEn 12/10/84). In some 
cases canine saviors demonstrated amazing cognitive and physical capacities ("Dog Saves Owner by Using CPR," Sun 1/19/88) and even magical powers ("Healing Dog Licks Sick to Cure Them," Sun 6/2/87).

Savior stories also described the heroic deeds of a variety of other species. Some, such as sea mammals, were predictable. There is a plethora of folktales describing humans rescued from drowning by porpoises. This is reflected in the tabloids, though sometimes with a different twist, as in the case of a dolphin that rescued a family dog that was swept off a ship (NEx 7/10/90). Less likely species occasionally play the role of tabloid lifeguard. In "Drowning Mom Saved by Killer Croc" (WWN 7/17/90) and "Crocodile Saves Drowning Boy" (Sun 6/9/87), one of the few species with a well-documented history of consumption of human flesh (Neill 1971) assumes this unexpected new role. But our nominee for the most unusual lifeguard was described in "A Giant Sting Ray Carried Me on Its Back for 16 Days!" (NEn 7/10/90).

Other unlikely animal saviors included a duck (it quacked and alerted the citizens of a German city that Allied bombers were approaching), a parrot, a pigeon, several horses, and Bigfoot. Certain animals were conspicuously absent in the savior category. Whereas the second most common family pet, dogs, were the most frequent animal heroes, the most common pet, the cat, was rarely represented in the savior category. One exception was the interspecific heroism depicted in "Lion-Hearted Kitty Attacks Pit Bull and Saves Poodle's Life" (NEn 4/3/90). Similarly, we came across no stories in which the heroes were sharks, spiders, snakes, or insects, reflecting the roles of these species as threats rather than saviors.

Animals in the tabloids saved humans and other animals from many different types of predicaments including drowning (7 instances), fire, mugging, freezing to death, coma, being shot, being attacked by animals, and disease. Some animals saved humans through unconventional medical practices, as in "These Suckers Save Lives" (Sun 11/3/87), an article on the medicinal application of leeches. Sometimes miraculous results were achieved via the human-animal bond, an offshoot of the affection theme ("Loving Horse Gives Leukemia Victim a New Will to Live and She Makes a Miracle Cure," WWN 3/18/86). Animals could also save by delivering messages ("Badly Wounded Pigeon Delivers Note that Saved US Soldiers," NEn 10/4/88), detecting illness ("Your Pet Can Read Your Mind," NEx 3/20/90); and being at the right place at the right time ("Cawing Crow Saves Woman from Mugger," Sun 7/17/90).

Table 3. Distribution of Species in the Vicious Category

\begin{tabular}{|cl|}
\hline Number of articles & Species \\
\hline 24 & Dogs \\
13 & Sankes \\
8 & Cats \\
7 each & Alligators and crocodiles, sharks \\
6 & Apes \\
5 each & Bears, fish \\
4 each & Birds, elephants \\
3 each & Bees, chickens, cows, and bulls, mosquitoes \\
2 each & Dolphins, hippotami, lions, panthers, rabbits, roaches, skunks, whales \\
& Bats, Bigfoot, camels, cougars, coyotes, dinosaurs, boars, ferrets, fire ants, fleas, \\
1 each & horses, hyenas, jellyfish, leeches, leopards, mermaids, moose, pests, rats, sea \\
& monsters, squirrels, spiders, tigers, toads, trees, turtles, werewolves \\
\hline
\end{tabular}

\section{The Animal as a Threat}

Whereas some animals are saviors, others are feared. We found 128 stories depicting the ways animals terrorized, harassed, or consumed humans or other "innocent" species. (Note that sexual assault by 
animals is a related theme that is treated separately.) As shown in Table 3, there was an impressive list of not-so-nice creatures. We found lots of stories involving traditional human enemies: sharks, bears, alligators, bats, various types of insects and spiders, elephants, snakes, etc. But less likely candidates also assumed vicious roles on occasion. These included cattle, chickens, werewolves, a "sea monster," toads, rabbits, chimpanzees, several species of fish, monkeys, pigeons, squirrels, a mermaid, whales, and, of course, Bigfoot. One of the most unlikely villains was the subject of the story "I Got Mugged by Mickey Mouse" (WWN 6/18/85).

Paradoxically, the dog, the most common subject of the savior and the affection stories, was also the most frequently implicated species in vicious animal items. This finding no doubt reflects the basic ambivalence that we have toward an animal that on the one hand is "man's best friend" but on the other is a predator (Beck and Katcher 1983). In some tabloid dog stories the adversarial relations between man and dog have a stereotypical component ("St. Bernard Bites Off Mailman's Leg," Sun 10/ 14/86). In others, there is a terrifying sense of betrayal of the relationship between human and "companion animal" ("Boy's Beloved Pet Tears His Face to Shreds," Sun 6/9/87).

Lacking rapid speed and having paltry claws and teeth, humans were no doubt culinary treats for a variety of large predators during much of our evolutionary history, and stories of predation on humans occasionally appear in the tabloids. There were 19 articles describing grisly tales of humans being eaten. Predictably, humans were eaten by lions, tigers, sharks, large snakes, and crocodiles. They were also consumed by less likely animals in search of a meal, including ferrets (they ate the fingers and noses off rich kids), dogs, mosquitoes, a parrot, pigs, a hippopotamus, and a "big fish."

Sometimes justice prevailed in animal violence stories. In a number of cases, animals extracted revenge on exploitive humans ("Thirty Hungry Dogs Devour Cruel Breeder" (NEx 4/9/85), "Snake Shoots Hunter to Death" (NEx 6/5/90), "Killer Trees Kill Greedy Developer" (NEx 7/16/85). In tabloid justice, husbands or wives often use animals to get back at unfaithful spouses: "Wife Turns Hubby into Shark Bait" (WWN 6/18/85), "Man Kills Wife with 1,000s of Starving Fleas" (Sun 5/27/86), "Leeches Suck Hubby Dry" (Sun 8/30/88). Other stories also described the use of animals by humans for less than honorable ends, as in the case of "Mafia Kills Victim by Feeding Him to Hogs" (Sun 4/30/85) and our personal favorite, "Sicko Uses Roaches to Torture Hookers" (Sun 1/29/85).

The terror of animal attacks in tabloids is frequently exacerbated by the inclusion of images in which parents observe their children being attacked ("Pit Bull Grabs Tot But Mom Chokes Dog to Death with Bare Hands" (WWN 9/10/85) and "Dad Battles Huge Snake in Brave Try to Save Son" (WWN 10/11/88), or "I Watched Helplessly as... A Giant Grouper Ate My Wife and Child" (Sun 5/8/90). In most cases parents at least try to repulse the attacking beast, but in one case the mother herself became the agent of violence-"Bats Made Me Kill My Kids" (Sun 7/16/85). The theme of this story is unwitting betrayal in that a mother commits infanticide because she is driven insane by the high frequency sounds given off by the bats living in her attic. The tables are turned, however, in "Heavy Metal Rock Turns Poodle into Vicious Killer" (Sun 3/24/87), a story describing how a loyal family dog was transformed into a villain through human agency (rock and roll music).

\section{The Animal as Victim}

In the preceding thematic category, humans are victims of animal aggression. In reality, animals are much more likely to suffer at human hands. Two types of articles were related to the the mistreatment of other creatures. In the first, involving animal welfare, humans work to save animals. In the second, cruelty, humans abuse them.

The welfare theme included 41 articles that focused on topics such as conservation efforts, the animal rights movement, and attempts to save individual animals. Typical articles described campaigns to save endangered species and pathetic-looking oil-soaked wildlife. Animal rights were the implicit focus of articles describing the mistreatment of laboratory animals. Other articles portrayed an animal welfare group that wanted to keep piglets from being kissed by throngs of people at a fundraiser (WWN 7/24/90) and the tale of how 150,000 snails were liberated from an escargot farm by animal rights activists (Sun 
5/8/90). Stories about individual acts of kindness toward animals were common: "Kennel Owner Going Broke to Save Dogs from Death" (Sun 7/17/90), "Widow Is Guardian Angel to Handicapped Animals" (Sun 1/12/88), and "Phantom Vet Cures Animals from the Grave" (NEx 10/4/88). In typical tabloid fashion, acts of kindness can go awry-"Man Swallows Kitten by Mistake... While Giving Mouth to Mouth Resuscitation" (Sun 1/9/90).

The theme of cruelty to animals was found in 71 articles. Many of these items chronicled what can only be described as torture, reminiscent of acts perpetrated on animals by young psychopaths (Kellert and Felthous 1985): "Kitty Cooked in the Microwave" (Sun 7/17/90), "Weirdo Tortures and Kills 77 Kittens" (Sun 7/17/90). Commonly, mistreatment of an animal was used to inflict pain on the animal's owner, as in "He Didn't Do His Homework So... Cruel Mom Kills Son's Hamster in Blender" (Sun 9/11/90) and "RolyPoly Pet Owner Barbecues Her Husband's Parrot-For Making Fat Jokes" (WWN 4/12/88). Indictments against social institutions rather than individuals are the subject of articles like "Sinister Fate Awaits Missing Pets... Pet Food... Laboratories... Furs!" (Sun 5/27/86), and "Outrage! Storm Over Minimatadors Who Torture Young Calves" (NEx 5/1/90), an article describing a group of Spanish midgets who aspire to be bullfighters.

\section{The Animal as a Tool}

Humans may have a natural tendency to dichotomize animals into those that we have a relationship with and those that we regard as things to be used (Arluke 1988; Russow 1989). Kellert (1980) has shown that the dominant orientation of many Americans toward other species is utilitarian, and 99 of the articles we examined portrayed animals as objects that could somehow be used in one way or another for human benefit.

While animals have a bewildering number of potential uses, the most fundamental is as food. With over 5 billion animals per year consumed in the United States (Gallup and Suarez 1987), the most frequent manifestation of the human-animal relationship on a daily basis is the act of eating the animal, a fact recognized by tabloid authors. Twenty-two items in our database focused on animal consumption. In almost all of these cases, the animal eaten was unusual, often giving the story a disgusting air. In five of these articles a species normally given the social role of pet was transformed into food, violating one of the most basic cultural distinctions between species (Leach 1989). The headlines "Butcher Sells Dog Instead of Rabbit" (Sun 1/9/90) and "Zoo Keepers Kill Cuddly Little Bear and Eat Her for Dinner" (WWN $5 / 3 / 88$ ) exemplify this theme.

Rats, featured in five articles, were the most frequently mentioned species in the context of the culinary arts. Other unusual consumables included worms, cockroaches, lizards, scorpions, rattlesnakes, and snails. In some stories, a disquieting element was added by the fact that the animal was eaten raw ("Lost Hunter Survives 2 Weeks By Eating Raw Birds and Rabbits," Sun 1/19/88) or alive ("Doc Removes $3 \mathrm{lb}$ Frog from Boy's Stomach!," Sun 3/8/88; "Swallows Canary on a BetNow All He Says Is Tweet Tweet," Sun 9/25/90), or by the unwitting consumption of an animal ("Pig Blood in Coke?" WWN 5/7/85; "Mice Krispies!" Sun 9/25/90).

The utilitarian theme was also manifested in other strange uses of animals. "Praise the Lord and Pass the Snakes" described the ritual use of poisonous snakes by a religious cult (WWN 5/8/90). Other articles typifying this category included "Hindus Wed Frog to Bring on Rain" (Sun 5/27/86), "Angry Owner Beats up Driver with Her Dog's Dead Body" (Sun 1/11/88), and "Jilted Lover Uses Trained Boa to Commit Suicide" (Sun 1/19/88).

Many tabloid articles portrayed animal use through their roles in entertainment and recreation. A plethora of performing animals appeared in the tabloids including whales, dolphins, sea lions, dogs, bears, elephants, and toads. Competitions pitting animals against each other, often while humans gamble on the outcome, are common in many cultures, and we uncovered articles and pictures on pig races, turtle races, buffalo races, ostrich races, turkey races, canine Frisbee-catching contests, and canary cockfights. 


\section{The Animal as Sex Object and Sexual Aggressor}

Zoophilia, the sexualizing of contact between the species, is far and away the most taboo subject in the area of human-animal relations, though its occurrence is probably more common than generally acknowledged. References to bestiality occur throughout recorded history and were a central part of Greek mythology (Allgeier and Allgeier 1988). In his classic survey of the sexual habits of Americans, Kinsey reported that $8 \%$ of men (17\% of those raised on farms) and about $3 \%$ of women had experienced orgasm as a result of sexual interactions with animals (Kinsey, Pomeroy, and Martin 1948). Further, about a third of males and $16 \%$ of females admitted to at least some erotic responses while observing animals mating (Kinsey et al., 1953). Certainly, zoophilia is a topic that holds a forbidden fascination for a substantial number of individuals.

The tabloids we examined contained 18 stories at least tangentially concerned with sexual relations between people and animals. In some cases the conjugal relation was implied, as in "Woman Gives Birth to $14 \mathrm{lb}$ Dog" (Sun 1/9/90) - the aforementioned case in which the father was a space alien. In others, the physical nature of the relationship was more explicitly stated ("Don Juan Dolphin Tries to Mate with Lady Trainer," Sun 5/8/90). The legend of Beauty and the Beast has a horrifying yet undeniably erotic element (Fiedler 1978), which was recast in a slightly different form in tabloid headlines such as "Gorilla Makes Girl Pregnant" (Sun 6/4/85) and "Mandrill Father of Kid" (NEx 7/16/85). The majority of bestiality stories involved female humans, but there were occasional exceptions ("Hiker Battles for Life with Sex-Crazed Stag," NEx 12/84, and "Hunter Needs 30 Stitches When a Raccoon Tries to Mate with His Cap!" Sun $4 / 26 / 88)$.

Unlike the distribution of species in the "affection" category, the species distribution in bestiality stories did not reflect the types of animals most likely to actually be involved in zoophilic activities-farm animals and dogs (Gebhard et al., 1965). The most common creature involved in tabloid sexual encounters with humans was Bigfoot ( 5 instances), followed by various apes and dolphins (4 instances each). The distribution may reflect the fact that the majority of cases (12) involved sexual aggression by animals rather than, as in the case of true zoophilia, the use of an animal by a human for sexual gratification.

\section{The Imaginary Animal}

One of the most bizarre motifs in legend and myth concerns tales of creatures that exist only in the human imagination. Articles describing strange and sometimes imaginary creatures were fairly common in the four tabloids (70 items). We found that such stories were sometimes difficult to classify, and the categories of genetic anomalies, imaginary creatures, animals having religious or supernatural powers, and human-animal chimeras tended to overlap.

Anomalies. Humans have probably always been fascinated by animal "freaks" such as two-headed and albino animals, and there were 12 articles related to this theme in the papers we examined. Three types of stories depicted biological anomalies. In the first, the anomaly appeared to be a natural genetic occurrence. There were pictures of a two-headed calf, a two-headed snake, and a lamb with six legs. The second type of anomaly story portrayed unfortunate beasts that were not naturally deformed but were victims of technology gone awry, a common theme in animal horror movies. These cases often took the form of radiation-induced mutations. Examples included "Foot-Long Cockroaches Terrorize Renters-Lab Mutants Escape" (Sun 1/19/88), "Five Monster Chickens Hatch from Radioactive Eggs" (Sun 8/30/88), and "Devil Rats... Mutant Monsters Sent to Invade the US!" (Sun 7/10/90). The third type of anomaly story depicted cases in which there was no actual biological mutation but the animal had the physical characteristics of another species. Examples included pictures of a grossly wrinkled pig that looked like a dog, and a dog that bore an uncanny resemblance to a mop.

Animals with Supernatural/Religious Powers. Animals have probably been associated with magic and religion since the origins of our species (Campbell 1988b). Animals were objects of sacrifice and the voice of the gods. They populated dreams and visions and, like Pinocchio's Jiminy Cricket and Yoda of Star Wars, offered spiritual guidance in times of crises. Numerous tabloid tales described animals that had psychic or other special powers-a hog that reads minds, dogs that see spirits, and a pig that flies. 
Occasionally, animals appeared to owners after the creature had died ("Family Haunted by the Ghost of Thanksgiving Turkey" (Sun 5/21/85). Religious stories involving animals were reflected in the themes of reincarnation, as in a NEx story that claimed boxer Mike Tyson was a pigeon in his previous life ("Iron Mike's a Bird Brain!" 3/20/90) and "Our Son was Reborn... as a Dog" (WWN 3/24/89).

The religious element in human thinking about animals was also reflected in stories about animals that were worshiped or that were the manifestation of deities ("Snake God from Hell Terrorizes Aztecs," WWN 10/11/88; "Tribe Sacrifices Male Virgins to Giant Flesh Eating Parrots," Sun 2/7/89; and "Villagers Worship Siamese Twin Cows," WWN 7/24/90). Pets were sometimes endowed with handy mystical powers including the ability to detect illness, predict tornadoes, and select winning lottery numbers.

Imaginary and Mythological Creatures. Mythical beasts are a ubiquitous part of human legends (South 1987), and numerous accounts of sea monsters, animal ghosts, dinosaurs discovered alive (usually in Africa), and devil cats were found in the tabloids we examined. The most common imaginary inhabitant was Bigfoot, whose escapades were chronicled in 11 articles. Bigfoot stories assumed several forms. In some Bigfoot was malevolent ("Bigfoot Kills Two Scientists," WWN 7/23/85). Occasionally, though, Bigfoot redeemed himself by a heroic act ("Bigfoot Helps Rangers Fight Forest Fire," Sun 12/27/88). Bigfeet were also sexually active. In some cases Bigfoot's amorous exploits with humans were forced ("Female Bigfoot Tried to Rape Me," Sun 6/25/85; and "Gay Bigfoot Molests Little Boys, NEx 7/16/85), whereas in others there was an element of consent ("Teen-age Beauty Marries Bigfoot," NEx 5/28/85; "I Was Bigfoot's Love Slave," Sun 5/27/86). We found several "actual" photographs of Bigfoot including one in which he is shown taking a shower in the woods (NEx 6/11/85) and another that was purported to be a photograph of a baby Bigfoot (Sun 2/28/89) -"He's one year old and cute as a button."

The Human Animal. Among the most interesting mythical animals are creatures that are part human and part animal. In the tabloids, we found these stories could be divided into those in which the subject is a literal man/beast chimera, those in which the transformation from man to animal was metaphoric rather than literal, and stories of humans raised with animals.

Chimeras. Classical mythology is replete with creatures like the satyr and minotaur, beasts that are part human and part animal. Modern manifestations of this motif are found in articles such as "Sperm Bank Horror... Goat Gives Birth to Half Human/Half Animal" (Sun 2/5/85) and "Fisherman's Wife Gives Birth to a... Lobster Baby" (Sun 9/25/90). The animal species involved in various chimeras included baboons, apes, sheep, goats, lizards, fish, and Bigfoot. In a few cases, normal humans were transformed into animals just as Gregor is transformed into a giant insect in Kafka's classic Metamorphosis. In the tabloids, people turned into a variety of creatures. The Sun (7/17/90) described the case of "Pelican Man" whose nose became beak-like after surgery (he lives on-an allfish diet). The Sun also contained a story entitled "Sewer Worker Turns into Toad" (1/12/88) in which a man develops warts all over his body after being exposed to a sewage treatment plant. The classic werewolf motif in which humans are periodically transformed into wolves (Cheilik 1987) is also common in tabloids ("Hubby Turns into a Vicious Werewolf," Sun 1/12/88; "Werewolf Kills 37," WWN 3/24/89).

Often, cases of chimeric transformation or the incorporation of animal parts into humans (or vice versa) involved themes related to misuses of technology. The tabloids were obsessed with the authentic case of Baby Fae, the infant girl who was implanted with a baboon heart. Subsequent tabloid reports included items such as "Russians Transplant Chimp's Heart into 30 Humans" (Sun 3/24/87), "Man-Beast Created in Laboratory" (Sun 6/9/87), "Russians Turn Basketball Player into Bigfoot" (Sun 5/2/89), and "Human Pig Raised by Scientists" (Sun 8/30/88), a classic example of a misleading headline (the story described the use of synthetic human growth hormones to facilitate weight gain in hogs). Unlike fairy tales, where animals are often turned back into humans after a stint as a beast (Bettelheim 1976), there were no accounts of animals literally turning into people (though, as discussed below, animals often assumed human characteristics).

In some tabloid stories people were transformed into animals in a metaphorical rather than a literal sense. These are cases of "zoomorphism" in which humans are endowed with animal characteristics. A paradigmatic case is described in "Man Goes Psycho After Losing Job and Becomes A... Human 
Termite!" (Sun 4/30/85), a story of a man who becomes upset after being fired and gnaws on wood. Similar stories included "My Crazy Aunt Thinks She's a Dog" (WWN 4/10/90); "Siamese Twins, 19, Crawl Like Spider" (Sun 11/3/87); and "Disease Makes Baby Smell Like Skunk" (Sun 11/3/87).

Feral Humans. The specter of humans being raised with animals is a perennial theme in myth (Romulus and Remus), fiction (Tarzan), and even developmental psychology (see Malson 1972). Readers of the tabloids are frequently treated to stories of feral humans, as in "Girl Raised by Wolves: Animals Still Worship Her Like a Goddess" (Sun 2/7/89), "Boy Raised with Parrots" (WWN 8/4/87), and "Teen Girl Raised by Kangaroos Hops 10 Foot Fence" (Sun 1/5/88).

\section{The Animal as a Person}

The converse of stories of people transformed into or acting like animals were articles in which animals assumed human characteristics. There were 77 tabloid articles and photographs depicting animals acting or looking like humans. In addition, almost all of the 33 cartoons had anthropomorphic themes. The anthropomorphic items fell into three of the categories identified by Lockwood (1989): superficial anthropomorphism, explanatory anthropomorphism, and personification.

Superficial anthropomorphism is the tendency to interpret biologically functional qualities of animals in human terms. Tabloid examples included a picture of ducklings following a carriage on their "Family Outing" (Ex 4/14/87), a close-up photograph of a "laughing" horse (Sun 5/9/89), and a story about fire ants who chew up electrical wires and burn down houses.

Explanatory anthropomorphism involves circular explanations of animal behavior in terms of human motivation. Examples included "Pet Dog Burns Down Family's Home" (he was angry at being left behind from the family walk) (Sun 1/12/88) and a case in which a cobra murdered a snake charmer for revenge (WWN 7/17/90). Personification, or the tendency to superimpose our desires and wishes on animals, was a common theme in tabloid articles and pictures. Personification was usually manifested in pictures of an array of species (e.g., dolphins, dogs, parrots, and even toads) dressed in a bizarre variety of human attire or engaging in uniquely human behaviors. Examples included a dog with a credit card (NEn 3/4/86), an elephant that drives a jeep (Sun 5/2/89), and "Scuba Doo," the scuba-diving dog (Sun 5/8/90).

\section{The Animal as an Object of Wonder}

As the popularity of nature shows on television attests, Americans are fascinated by recent discoveries in the field of animal behavior. Despite the proliferation of pseudoscience in tabloids (Hinkle and Elliot 1989), they also contain legitimate reports on strange facets of natural history. Typical of the 106 items in this category was a story describing a species of frog whose skin darkens 12 hours before a rainstorm (WWN 1/23/90) and an article on birth control in cockroaches (WWN 4/1/86). The WWN sometimes contains a column entitled "Trivia: Little Known Facts to Astound Your Friends," which informs readers that bats' knees bend backwards and black widow spiders only kill 1 in 25 victims (4/1/86). The NEn has periodically published "The Incredible World of Animals," a column featuring unusual species such as flashlight fish and tarantula hawk wasps. Also representing this theme were reports of research on the topic of humans' relationships with their pets and descriptions of frivolous animal behavior studies funded by the federal government ("Stupid Study Will Make Taxpayers Hopping Mad," NEn 7/3/90; "Which Newts Are Sexiest? You Are Paying to Find Out," NEn 7/17/90).

Another group of stories related to the theme of animals as objects of wonder included stories describing amazing "facts" about individual animals. Some of these articles and pictures portray animals that are special simply by virtue of their size: the world's smallest bird (NEn 7/16/85), a 316-pound dog (NEx $7 / 17 / 90$ ), the largest salmon caught in 60 years (Sun 11/3/87). More often, though, the "amazing" distinction is earned through a special feat: "World's Biggest Beetle Crushes Aluminum Cans (Sun 5/2/89) and "Mouse Trots 550 Miles to Get Home!" (WWN 11/8/88). These feats may be plausible, but this category also included daring acts that cross over into the bizarre and incredible: "Cat Survives Wet-nWild Ride in Washing Machine" (Sun 6/16/87), "Lucky Cat Still has 8 Lives After 14 Story Fall" (WWN 10/ 31/89), and "Dog Lands Plane" (Sun 7/10/90). 


\section{Miscellaneous Themes}

Not all of the articles and pictures found in the tabloids fell into one of the major thematic categories. Fiftyseven of the items in our database defied our thematic category system and were considered miscellaneous. An article in the WWN describing how a dog dug up a corpse at a family picnic (5/7/85) is an example. Other examples included "Skunk Busters," an occupational role filled by individuals who remove unwanted visitors for a living (NEx 5/1/90) and "Liberace's Dog May Have AIDS" (Sun 3/24/87). Pictures of tortoises being wheelbarrowed to indoor cages at a zoo and a photograph of a young boy inside a cage of hungry tigers (Sun 7/10/90) are characteristic of the hodgepodge of features that we considered miscellaneous.

\section{DISCUSSION}

The study of popular culture can shed light on our feelings and behavior. For example, in a strange twist, we found that the portrayal of human-animal relations in the tabloids may be more accurate than more rigorous sociological data sets. Kellert (1980) conducted an extensive survey of Americans' attitudes toward animals based on a random sample of 3,107 individuals. One of the more curious findings of his study was that, when asked how they felt about different species, the respondents ranked cats 11thbetween turtles and ladybugs. As Quaman (1985) has pointed out, this result is anomalous in a country where cats recently overtook dogs as the most popular mammalian pet. The distribution of species found in tabloid items related to the theme of human-animal affection (Table 1) is a more accurate reflection of how we feel about cats than a careful scientific survey.

Bettelheim (1976) used fairy tales as a vehicle for understanding the psychic processes of children. Similarly, we have used the stories that appear in a popular medium to examine archetypal themes inherent in human-animal relations. In some ways, these bizarre stories are like the blobs of colored ink on cardboard in the Rorschach Test, the tool that psychologists use to access the human unconscious. Like the inkblot test, tabloid items tell us something about ourselves and perhaps our unconscious processes. Interestingly, animal themes are the most common single set of responses given to Rorschach stimuli (Exner 1990).

Since the dawn of our species, humans have confronted other creatures with fear, respect, revulsion, affection, or indifference (Campbell 1972). These basic responses to animals are reflected in mythological themes that occur across cultures and time. Our society has witnessed dramatic technological and cultural changes, and our relations with other species are often not as direct as in the past. Our popular culture, however, continues to reflect the same themes as the myths, legends, and artistic images of our forebears. Is it possible that the animal-related stories and photographs in modern tabloids in some ways retell the tales originally told around the flickering campfires of Lascaux tens of thousands of years ago?

\section{REFERENCES}

Allgeier, A.R., and E.R.Allgeier. 1988. Sexual interactions.Lexington, Mass.: D.C.Heath.

Arluke, A.B. 1988. Sacrificial symbolism in animal experimentation: Object or pet? Anthrozoös 2(2):97116.

Baenninger, R. 1988. Animals in art: Some trends across the millennia. Journal of Psychology 122(2):183-91.

Beck, A., and A.Katcher. 1983. Between pets and people: The importance of animal companionship. New York: G.P.Putnam's Sons.

Bettelheim, B. 1976. The uses of enchantment. New York: Alfred A.Knopf.

Bryant, C.D. 1979. The zoological connection: Animal related human behavior. Social Forces 58:399421.

Campbell, J. 1988a. The first story tellers. In The power of myth, ed. B.S.Flowers. New York: Doubleday.

. 1988b. Historical atlas of world mythology, Vol. 1: The way of the animal powers. New York: Greenwood Press.

__. 1972. Myths to live by. New York: Bantam Books. 
Cheilik, M. 1987. The werewolf. In Mythical and fabulous creatures, ed. M.South. New York: Greenwood Press.

Exner, J.E. 1990. A Rorschach workbook for the Comprehensive System, 3rd ed. Asheville, N.C.: Rorschach Workshops.

Fiedler, L.A. 1978. Freaks: Myths and images of the secret self. New York: Simon and Schuster.

Fox, R.F. 1988. Sensationspeak in America. English Journal 77(3):52-56.

Gallup, G.G., and S.D.Suarez. 1987. Antivivisection: Questions of logic, consistency, and conceptualization. Theological and Philosophical Psychology 7(2):81-93.

Gebhard, P.H., J.H.Gagnon, W.B.Pomeroy, and C.V.Christenson. 1965. Sex offenders: An analysis of types. New York: Harper and Row and P. B.Hoeber, Medical Books.

Gould, S.J. 1979. Mickey Mouse meets Konrad Lorenz. Natural History 88:30-36.

Hinkle, G., and W.R.Elliot. 1989. Science coverage in three newspapers and three supermarket tabloids.

Journalism Quarterly 66(2):353-58.

Kellert, S.R. 1980. American attitudes toward and knowledge of animals: An update. International Journal for the Study of Animal Problems 1(2):87-119.

Kellert S.R., and A.R.Felthous. 1985. Childhood cruelty toward animals among criminals and noncriminals. Human Relations 38(12):1113-29.

Kellert, S.R., and M.O.Westervelt. 1982. Historical trends in American animal use and perception. Transactions of the 47th North American Wildlife and Natural Resources Conference. Washington, D.C.: Wildlife Management Institute.

Kelm, R.S. 1990. The lack of access to back issues of the weekly tabloids: Does it matter? Journal of

Popular Culture 23:45-50.

Kinsey, A.C., W.Pomeroy, and C.Martin. 1948. Sexual behavior in the human male. Philadelphia: Saunders.

Kinsey, A.C., W.Pomeroy, C.Martin, and P. Gebhard. 1953. Sexual behavior in the human female. Philadelphia: Saunders.

Lawrence, E.A. 1989. Neotony in American perceptions of animals. In Perceptions of animals in American culture, ed. R.J.Hoage. Washington, D.C.: Smithsonian Institution.

Leach, E. 1989. Anthropological aspects of language. Anthrozoös 2(3):151-65.

Lehnert, E., and M.J.Perpich. 1982. An attitude segmentation study of supermarket tabloid readers. Journalism Quarterly 59(1):104-11.

Levin, J., A.Mody-Desareau, and A.Arluke. 1988. The gossip tabloid as agent of social control. Journalism Quarterly 65(2):514-17.

Lockwood, R. 1989. Anthropomorphism is not a four letter word. In Perceptions of animals in American culture, ed. R.J.Hoage. Washington, D.C.: Smithsonian Institution.

Malson, L. 1972. Wolf children and the problem of human nature. New York: Monthly Review Press.

Manning, M., ed. 1989. The National Directory of Magazines, 2nd ed. New York: Oxbridge Communication.

Neill, W.T. 1971. The last ruling reptiles: Alligators, crocodiles and their kin. New York: Columbia University Press.

Nordheimer, J. 1988. Mild-manner buyers tame wild tabloids. New York Times, February 4:9+.

Quaman, D. 1985. Natural acts. New York: Nick Lyons Books.

Russow, L.M. 1989. Changing perceptions of animals: A philosophical view. In Perceptions of animals in American culture, ed. R.J.Hoage. Washington, D.C.: Smithsonian Institution.

Salwen, M.R., and R.B.Anderson. 1984. The uses and gratifications of supermarket tabloid reading by different demographic groups. Paper presented at the August 1984 Annual Meeting for Education in Journalism and Mass Communication.

Serpell, J.A. 1986. In the company of animals. New York: Basil Blackwell.

South, M., ed. 1987. Mythical and fabulous creatures. New York: Greenwood Press.

ten Bensel, R.W. 1984. Historical perspectives of human values for animals and vulnerable people. In The pet connection, eds. R.K.Anderson, B.J. Hart and L.A.Hart Minneapolis: Center to Study Human-Animal Relationships and Environments. 